\title{
Controle de legalidade do ato jurídico-administrativo praticado na atividade de inteligência: o caso do Estado Democrático de Direito brasileiro
}

\author{
Control of legality of the juridical and administrative act practiced in the intelligence \\ activity: the case of the Democratic State of brazilian Law
}

\author{
Durbens Martins Nascimento* \\ Wando Dias Miranda* \\ Roberto Magno Reis Neto ${ }^{* * *}$
}

\section{Resumo}

Considerando a importância estratégica inerente à atividade de inteligência num contexto mundial e nacional, bem como levando em conta o "temor" historicamente imputado a esta função, com vistas a propiciar uma aplicação do debate político-jurídico do tema, assim como o aperfeiçoamento de seus elementos, o presente estudo se debruçou sobre o objetivo de enquadramento jurídico dos atos praticados no exercício da atividade em apreço, elencando os elementos legais caracterizadores de sua validade. Para tanto, em um primeiro momento, tergiversamos sobre a ideia de democracia e da função da atividade de inteligência neste contexto. E, por conseguinte, restringindo-nos à inteligência de Segurança Pública, buscamos o enquadramento jurídico dos atos praticados pelos agentes e analistas desta área. Por fim, após as etapas anteriores, nos detivemos sobre uma análise crítica dos elementos de validade dos atos jurídico-administrativos praticados na atividade de inteligência em segurança pública, enunciando lacunas e perspectivas de controle dos referidos atos, obviamente, em busca de sua legitimação dentro de nosso regime democrático.

Palavras-chave: Atividade de inteligência. Segurança pública. Atos jurídico-administrativos de inteligência. Elementos de validade.

\section{Abstract}

Considering the strategic importance inherent in intelligence activity in a global and national context, and taking into account the historically imputed "fear" of this function, with a view to facilitating an application of the political-legal debate on the subject, as well as improving of its elements, the present study focused on the objective of legal framework of the acts practiced in the exercise of the activity in question, listing the legal elements characterizing its validity. To do so, in a first chapter, we misrepresent the idea of democracy and the function of intelligence activity in this context. And, therefore, restricting us to the intelligence of Public Security, we seek the legal framework of the acts practiced by the agents and analysts of this area. Finally, after the previous steps, we focused on a critical analysis of the elements of validity of legaladministrative acts practiced in the activity of intelligence in public security, enunciated gaps and perspectives of control of said acts, obviously, in search of its legitimation within of our democratic regime.

Keywords: Intelligence activity. Public security. Legal-administrative acts of intelligence. Elements of validity.

Doutorado em Ciências: Desenvolvimento Socioambiental. PH. D em Sociedade e Natureza (UFPA). Professor do Núcleo de Altos Estudos Amazônicos - NAEA/UFPA. Coordenador Geral do Projeto Rede Brasil-Amazônia para Gestão Estratégica em Defesa, Segurança e Desenvolvimento - Pro-Estratégia/CAPES. Diretor Geral do NAEA/UFPA. Belém-PA-Brasil. E-mail: durbens.naea@gmail.com.

- Doutorando em Planejamento do Desenvolvimento pelo NAEA/UFPA. Mestre em Ciência Política pelo PPGCP/UFPA, com ênfase em Relações Internacionais, Políticas Públicas de Defesa, Fronteira e Amazônia. Especialista em Gestão Estratégica em Defesa Social pela Universidade Estadual do Pará (UEPA) e Atividade de Inteligência e Gestão do Conhecimento (ESMAC). Pesquisador do Observatório de Estudos de Defesa da Amazônia (OBED). Belém-PA-Brasil. E-mail: wandomiranda@outlook.com.

...* Mestrando em Segurança Pública, junto ao Instituto de Filosofia e Ciências Humanas da Universidade Federal do Pará (IFCH/UFPA). Especialista em Direito Processual Civil pela Universidade Gama Filho/DF. Docência Superior na Universidade Gama Filho/DF. Professor Universitário na Escola Superior Madre Celeste. Instrutor no Instituto de Ensino de Segurança Pública do Pará - IESP. Belém-PA-Brasil. E-mail: bob_reis_ufpa@ yahoo.com.br. 


\section{Introdução}

O tema deste artigo é a atividade de inteligência para preservação da integridade e estabilidade dos Estados. Especificamente, analisaremos o caso do Estado Democrático de Direito brasileiro. As pesquisas em diversas áreas demonstram que o tema vem crescendo em interesse. Nota-se, historicamente, uma vasta produção científica nos países anglo-saxônicos, EUA e Inglaterra, em particular (STEELE, 2001), e também na Ex-URSS, atualmente na Rússia, em Israel e na China. Ao passo que, na América Latina (CANO, 1965) e no Brasil, essa produção é incipiente e recente (CEPIK, 2001; SANTOS, 2015; CEPIK; KUELE, 2016). A centralidade geopolítica dessas nações nos tempos da Guerra Fria e a mudança do eixo geopolítico, na contemporaneidade, para a Ásia explicam, em parte, essa tradição. Ressalta-se o caráter estratégico dessa atividade, tanto para preservação da soberania estatal num contexto internacional quanto para propiciar um status mínimo de ordem interna (GONÇALVES, 2009, p. 5-6).

Contudo, a despeito dessa relevância, é assente a existência de um verdadeiro "pavor social" à execução de medidas voltadas à obtenção dos "conhecimentos sensíveis" necessários à condução dos processos decisórios determinantes àquela pretendida ordem, quase que numa relação de proporcionalidade inversa.

Trata-se de um "estigma" decorrente dos métodos de "coleta de informações"1 peculiares ao período anterior à democracia brasileira (em muito, atribuído às práticas concernentes ao regime ditatorial instalado a partir de 1964), ao longo do qual se associou uma imagem de "repressão política" e "violação às liberdades e direitos fundamentais" à atividade de inteligência (ANTUNES, 2002, p. 30).

Surge disto uma interessante dicotomia: se, por um lado, é de inescusável interesse público a manutenção da ordem estatal, seja no plano externo, seja no plano interno; por outro lado, poucos são os que aceitam, pacificamente, qualquer espécie de investigação ou observação de suas atividades particulares, como se sua vida configurasse uma redoma de individualidade intangível e intransponível.

Noutras palavras: temos que todos anseiam que o Estado investigue atividades potencialmente nocivas a seus interesses (e aos interesses públicos), porém poucos aceitam ser investigados, inobstante saibamos da nossa potencialidade delitiva.

Por óbvio, a permanência do estigma é atribuível, em muito, à ausência de uma discussão verdadeiramente aberta, tanto doutrinária quanto política e popular, a respeito das peculiaridades da inteligência, bem como à não demonstração dos mecanismos pelos quais essa atividade pode ser efetivamente controlada, interna e externamente, em cada uma das fases do ciclo de sua produção - solicitação, coleta, análise e disseminação de resultados (GONÇALVES, 2009, p. 5).

O controle desse instrumento de ação estatal, aliás, ganha uma relevância especialíssima no contexto do regime democrático. Primeiramente, em razão da necessidade de participação popular nas políticas públicas a serem implementadas pelo Estado (inclusive, as de inteligência, a despeito de seu caráter normalmente sigiloso). Em segundo lugar, em razão da limitação da atuação executiva deste último diante do núcleo intangível dos direitos fundamentais do cidadão, notadamente sua liberdade material e ideológica, privacidade, sigilo de comunicação, inviolabilidade domiciliar e integridade física.

Compreender, portanto, os mecanismos de controle da atividade de inteligência, invariavelmente, afigura-se fundamental à própria confiabilidade desse mecanismo de tutela de interesses públicos, o que, por sua vez, repercute na própria legitimidade da atuação dos agentes e órgãos de inteligência no Estado Democrático.

Nesse contexto, por sua vez, é inevitável o questionamento: quais são os mecanismos de controle existentes em torno da atividade de inteligência, tanto num plano político quanto num plano jurídico? Especialmente: quais são os elementos caracterizadores da legalidade dos atos praticados no exercício da

Aqui ressaltando, conforme a lição de Antunes (2002, p. 43), que a utilização da terminologia "informações" é típica da atividade de inteligência anterior à década de 1990. 
atividade de inteligência em nosso Estado Democrático? Sobre esse segundo questionamento, pretendemos nos debruçar.

Por óbvio, é necessária a realização de um "corte epistemológico" imprescindível ao estudo; primeiramente, diante do fato de que a atividade de inteligência pode denotar um viés tanto externo (voltado às relações internacionais) quanto interno (voltado à segurança pública e demais atividades estratégicas), conforme assinala Gonçalves (2009, p. 21-22), detentor, cada um, de características marcantes. E, em segundo lugar, em função do fato de que a inteligência, como atividade executiva do Estado, se denota como um processo que nasce num nível político e se concretiza num nível administrativo, em que os mecanismos de controle podem ser bastante diferenciados, tanto na teoria quanto na prática.

Em razão disso, nossa problemática estará direcionada, neste estudo, ao âmbito da atividade de inteligência em segurança pública, em seu aspecto administrativo, ou seja, executivo ou operacional.

O debate é de extrema significância: para o âmbito da inteligência, denota argumentos, como dito, imprescindíveis para sua legitimação e concretização social. Para o âmbito jurídico, a temática propicia o desenvolvimento de uma doutrina preventiva e repressiva de condutas juridicamente prejudiciais ao ordenamento vigente, sobretudo aos direitos fundamentais do cidadão.

Ademais, trata-se de assunto que, por suas próprias características, toca num ponto deveras polêmico, já que a atividade de inteligência, como instrumento de investigação de ameaças potenciais ao sistema, necessita de uma "metodologia própria" que, sem demagogias, atua no extremo limite da noção de legalidade, transitando numa fronteira muito tênue e fácil de ser ultrapassada.

Como objetivo do artigo, pretendemos identificar e analisar, a partir do modelo jurídico e legislativo do Estado Democrático de Direito brasileiro, os elementos de controle da validade do ato praticado no exercício da atividade de inteligência, a partir de um aspecto de legalidade, como dito acima.

Especificamente, buscaremos enquadrar os atos de inteligência dentro de uma das categorias de atos jurídico-administrativos previstos pela doutrina brasileira, tomando como base o paradigma democrático em que vivemos. Em seguida, verificaremos, a partir do ordenamento jurídico concebido no atual estágio do Estado brasileiro, quais seriam os elementos necessários à caracterização da legalidade dos atos em questão. Por fim, satisfeitas essas premissas, definiremos quais seriam os critérios determinantes da validade dos atos jurídico-administrativos de inteligência, consideradas suas peculiaridades e "metodologia própria".

Adotaremos o método exploratório (uma vez que busca definir pontos ainda obscuros relativos à atividade em menção), sob nítido viés hipotético-dedutivo, já que parte de uma hipótese pré-definida a ser verificada (MEZZAROBA; MONTEIRO, 2014, p. 94-96), perfazendo-se através de uma pesquisa bibliográfica e documental, portanto, debruçada sobre a doutrina especializada e sobre a legislação pertinente à questão em análise (PÁDUA, 2012, p. 193-194).

\section{Enquadramento jurídico dos atos praticados na atividade de inteligência em Segurança Pública no contexto do Estado Democrático de Direito brasileiro}

Inicialmente, é importante buscar uma definição conceitual satisfatória a respeito do que caracterizaria o reputado "Estado Democrático de Direito" estabelecido em nosso território. Obviamente, sem devanear em torno de qualquer noção apaixonada ou axiologicamente neutra.

Nesse sentido, partindo dos ensinamentos de Fernandes (2014, p. 285) podemos compreender que "a ideia de democracia não é ideal, mas configura-se pela existência de procedimentos ao longo de todo o processo decisório estatal, permitindo e sendo poroso à participação dos atingidos, ou seja, da sociedade".

Não se trata, portanto, de um sistema no qual será "inequívoca" a participação de todos os atores sociais. Afinal, num contexto de diferenças e exclusões, tergiversar sobre uma "democracia ideal" seria ignorar a existência de interesses dominantes (hegemônicos), que se sobrepõem aos de outros grupos sociais, os quais, por vezes, estão desprovidos de voz e participação, porém, ainda assim, capazes de exercer potenciais pressões (contra-hegemônicas) na luta por um maior espaço político, econômico e social, 
traduzindo uma moderna dicotomia, existente tanto num cenário mundial quanto brasileiro (SANTOS, 2013, p. 64-68).

Interpretar, portanto, a declaração constitucional de que vivemos numa democracia, é, acima de tudo, compreender que o que determinaria o caráter "democrático" de nosso Estado, em termos pragmáticos, é a possibilidade (em maior ou menor grau) de participação popular (direta ou indireta) na tomada dos processos decisórios inerentes à construção e execução de políticas públicas, ao invés de uma "imposição unilateral das mesmas".

Deve-se lembrar, aliás, que o Brasil, como país de proporções continentais, não compreende um só "Brasil", mas vários "Brasis", pois a multiplicidade de nossa cultura, práticas, povos originários, modelos religiosos, movimentos e grupos de pressão social, dentre vários outros fatores, afiguram-se como elementos determinantes para a aceitação e viabilidade das ações estatais, de modo a se afirmar, sem exagero, que um mesmo modelo de política pode se adequar, perfeitamente, a uma região e ser absolutamente impróprio a outra (FARIAS NETO, 2011, p. 152-154).

Por isso afirmamos, sem embargo, que o modelo ideológico de Estado Democrático de Direito é um "paradigma" (FERNANDES, 2014, p. 285) que orienta a ação estatal em prol das necessidades de "diferentes formatações" de uma mesma "sociedade civil", sob o desiderato de realização dos objetivos constitucionais: liberdade social, desenvolvimento, erradicação da pobreza, bem-estar, etc.

De fato, devemos ressaltar que esse modelo é "ideal”, já que, na prática, são incontáveis as dificuldades a sua implementação, o que pode gerar substanciais questionamentos quanto à "qualidade do seu funcionamento". Santos (2013, p. 270), por exemplo, afirma que a expansão da participação popular para além do "voto" pode ocasionar o surgimento, até mesmo, de um novo paradigma político estatal, para além de estruturas legitimadoras de "situações arraigadas no tempo", o que, perante "mentes menos abertas à mudança", pode significar uma verdadeira "ameaça à estabilidade e longevidade das instituições estatais".

O debate é interessante, mas, infelizmente, não cabe nas presentes linhas por força dos objetivos eleitos. De todo modo, a partir desses poucos parágrafos já podemos ter uma noção de democracia como "processo", e não como modelo inerte.

Determinante, ao passo, é destacar que o alinhamento de políticas públicas num Estado declarado como "Democrático de Direito" deve observar dois fatores: a) a multiplicidade social, que roga uma participação popular na elaboração das ações políticas, tanto na fase de elaboração quanto na fase de implementação; e b) a observância de normas jurídicas previamente elaboradas (em concordância ao primeiro preceito), que ditarão os processos a serem seguidos, as formalidades necessárias e imprescindíveis à validade daquelas ações, em respeito a um princípio democrático segundo o qual "as regras do jogo" estarão bem delineadas a todos, possibilitando controles prévios, concomitantes e/ou posteriores.

É se advertir, entretanto, que assim como não se pode falar "numa só sociedade", igualmente não se pode falar "num só governo" ou "num só direito", somente em espaços contraditórios, forças políticosociais em confronto, distantes de formar o que muitos apregoam como um "bloco monolítico ou plenamente hegemônico de poder", ainda que se possa falar na existência de uma "hegemonia conservadora" (BEHRING; BOSCHETTI, 2006, p. 198).

Diante disso, surge o questionamento: em face de tamanha volatilidade política, como estabelecer um parâmetro mínimo de funcionamento das políticas estatais, sobretudo das políticas de inteligência? Como garantir o uso ético da máquina pública? Como aferir um mínimo de legitimidade dessas ações estatais?

Certamente, a construção de instâncias comunitárias de participação, de integração social e política e, sobretudo, de controle, dentre outros, é medida de extrema importância. Porém, para que se chegue a tanto, é imprescindível o estabelecimento de um regramento inicial de caráter vinculante, capaz de coordenar as ações de quaisquer potenciais detentores do poder (sejam sujeitos hegemônicos, sejam contra-hegemônicos), no sentido de promover um desenvolvimento equilibrado de políticas e decisões estatais sem condutas predatórias. 
Esse parâmetro inicial, a nosso ver, pode ser obtido a partir da "lei". Afinal, se o Estado, além de democrático, é um "Estado de Direito", suas instituições devem obediência a um regramento mínimo, em tese, elaborado em atenção a um processo de convergência de forças (por vezes antagônicas, como vimos).

É claro que não podemos ignorar que a institucionalização de normas e conflitos acaba por se configurar como mecanismo de filtragem de interesses, cooptação de demandas e favorecimento de camadas hegemônicas do organismo social, ocupando a lei, nesse contexto, uma função de "organizadora" da "violência estatal", responsável por legitimar privilégios estatais em detrimento de largas camadas da comunidade, como afirma Miguel (2015, p. 40).

À luz dos ensinamentos de Foucault (2015, p. 68-69), o norte ora adotado poderia, por um lado, ser facilmente desqualificado sob a velha argumentação (de nítido viés marxista) de que a lei (portanto, o direito posto) é um instrumento de exclusão social, utilizado como mecanismo de criminalização de condutas não desejadas por grupos detentores de poder (o que, em larga medida, não pode ser negado, admitimos).

Porém, por outro lado, não podemos ignorar que o modelo de ordem instituído a partir da lei, apesar de não ser o ideal, é um mínimo modelo de garantia de ordem social que não pode ser simplesmente "dispensado" sem graves riscos à comunidade instituída. Igualmente, o "Direito" funciona como um parâmetro de limitação reconhecido pelo Estado em relação aos seus atos políticos ou administrativos, o que, nessa qualidade, serve como uma "primeira instância" de discussão e controle daquelas ações, ao menos para fins de revelação das "lacunas institucionais" a serem supridas em eliminação ao "mau funcionamento" das instituições.

Compreendemos que a ressignificação (ou releitura) da lei à luz da Constituição Federal, como exigência típica de um Estado Democrático de Direito, impõe a derrogação de qualquer prática legal que venha a sufragar de validade os ideais de igualdade e liberdade (dentre outros) relativos a qualquer cidadão, sobretudo no que se refere à "garantia de ser diferente", o que, apesar de ser algo dificultoso de se realizar na prática, ainda assim, é uma ação cabível na eliminação de desigualdades materiais alimentadas pelo próprio sistema político-econômico.

Quanto à atividade de inteligência, aliás, esta busca pela aplicação do ideário constitucional revela um fato interessante: compreendemos que o controle da atividade de inteligência, no atual contexto democrático, não exige que se estenda, sobre os hoje compreendidos como "desfavorecidos", a mesma "armadura protetiva" que se colocou, historicamente, sobre a personalidade de muitos sujeitos "privilegiados", política, social ou economicamente. Do contrário, a Constituição, em sua exigência de igualitário tratamento das questões de interesse público, impõe que a atividade de inteligência haja de forma ostensiva (porém, respeitosa) sobre todos aqueles envolvidos em fatos relevantes, do simples cidadão ao parlamentar ou alto integrante de escalões governamentais, ${ }^{2}$ ou privados, sem distinções.

Falar de controle e de uso ético da máquina pública, portanto, no contexto de um Estado Democrático de Direito, importa reconhecer, num primeiro momento, a existência de uma normatização mínima que estabeleça os limites das ações dos agentes públicos, no exercício de sua competência, de modo a equilibrar as relações políticas e possibilitar a instalação de instâncias colegiadas de controle, justamente para exercício democrático dos mecanismos institucionais.

Afinal, como bem adverte Gonçalves (2009, p. 21), a atividade de inteligência é uma função diretamente destinada ao agente político tomador de decisões, pelo que se traduz como instrumento colocado à disposição das estruturas estatais, portanto, regulado conforme uma produção normativa pública prévia (a qual, ao menos em tese, deve se constituir a partir do ideal da "vontade popular").

Assim sendo, considerando-se a atividade de inteligência como uma política estatal contextualizada no modelo democrático de Estado, temos que sua qualificação deve se originar a partir do próprio direito público vigente, como passaremos a ponderar no tópico seguinte.

Não que esse ideal já não esteja implicitamente conclamado na lei. Mas, em tempo, devemos lembrar que não há lei que se aplique de forma ética se seu aplicador também não o proceder dessa maneira. Afinal, a má aplicação do paradigma não impõe sua falseabilidade, senão a melhoria de seus mecanismos de controle, o que resvala frontalmente em nosso estudo. 


\title{
3 Qualificando a atividade de inteligência no contexto do Estado Democrático de Direito
}

Partindo de nossa legislação, temos que a atividade de inteligência pode ser conceituada como a função que objetiva a obtenção, análise e disseminação de conhecimentos, dentro e fora do território nacional, sobre fatos e situações de imediata ou potencial influência sobre o processo decisório, a ação governamental e a salvaguarda e a segurança da sociedade e do Estado. ${ }^{3}$

É assente que essa atividade pode ser realizada, como dito, em diversos níveis, áreas do conhecimento e espaços de atuação política estatal; o que, por sua vez, denota a existência de diversas "atividades de inteligência" (estratégica, militar, fiscal, etc.). Contudo, como também afirmamos em momento anterior, deteremos nosso foco sobre a atividade de inteligência em Segurança Pública. Conforme prescreve a Doutrina Nacional de Inteligência em Segurança Pública,

\begin{abstract}
A atividade de ISP (inteligência em Segurança Pública) é o exercício permanente e sistemático de ações especializadas para a identificação, acompanhamento e avaliação de ameaças reais ou potenciais na esfera de Segurança Pública, basicamente orientadas para produção e salvaguarda de conhecimentos necessários para subsidiar os governos federal e estaduais a tomada de decisões, para o planejamento e à execução de uma política de Segurança Pública e das ações para prever, prevenir, neutralizar e reprimir atos criminosos de qualquer natureza ou atentatórios à ordem pública (BRASIL, 2009, p. 10).
\end{abstract}

Trata-se, ex vi, de uma função intrinsecamente ligada à atividade de Segurança Pública, constitucionalmente definida, por sua vez, como um "dever do Estado, direito e responsabilidade de todos", cujo intento é "a preservação da ordem pública e da incolumidade das pessoas e do patrimônio" (BRASIL. CF, 1988).

Especificamente, quanto à finalidade da Atividade de Inteligência em Segurança Pública, ressalta Gonçalves (2009, p. 31) que,

[...] a inteligência policial tem por escopo, basicamente, a produção de provas de materialidade e autoria de crimes, ou seja, por meio da análise sistemática de informações disponíveis, busca a identificação de criminosos e os aspectos essenciais da consumação do delito. Há que se considerar, ainda, seu caráter consultivo, quando contribui para elaboração e adoção de medidas ou políticas de prevenção e combate à criminalidade.

Contudo, sua função vai muito além do enunciado acima. As informações obtidas através da inteligência, igualmente, podem ser utilizadas para orientação das instâncias superiores quanto à alocação de recursos materiais, econômicos e humanos (policiamento orientado à resolução de problemas), bem como para fins de estabelecimento de instâncias de diálogo com a população e sugestão de políticas públicas a serem implementadas por outros órgãos da administração pública (policiamento comunitário) (AZEVEDO; RICCIO; RUEDIGUER, 2011, p. 14-16).

Trata-se, portanto, de um importantíssimo viés preventivo e repressivo utilizado como importante instrumento da atividade de Segurança Pública, constitucionalmente declarada, como vimos, como um inexorável dever do Estado Democrático de Direito, portanto, indispensável instrumento público de ação estatal.

Aliás, a própria dicção do art. 144 da Constituição Federal declara a atividade de Segurança Pública (e, na mesma esteira, a inteligência em segurança pública) como uma função nitidamente atribuída aos "órgãos públicos", instituídos e com atribuições delineadas em igual nível constitucional.

É inegável (para não se dizer "evidente"), portanto, o caráter "público" da atividade de inteligência em segurança pública, o que é fundamental para que se compreenda, desde logo, uma premissa inafastável deste estudo: sendo pública essa atividade, é inegável sua submissão a um estatuto jurídico de "direito público", o qual é típico, portanto, do direito administrativo. Não à toa, a Doutrina Nacional de Inteligência

Art. $1^{\circ}, \S^{\circ}$ da Lei $n^{\circ} 9.883 / 99$, que Institui o Sistema Brasileiro de Inteligência - SISBIN e promoveu a criação da Agência Brasileira de Inteligência $-\mathrm{ABIN}$. 
em Segurança Pública (BRASIL, 2009, p. 14) submete os atos de inteligência aos princípios constitucionais aplicáveis à "Administração Pública" (Art. 37, caput da CF/884), dentre outros.

E, tal qual a atividade de "Administração Pública" (em sentido amplo), temos que a "atividade de inteligência em segurança pública" pode se realizar em dois níveis distintos: um nível político (constitucional ou governamental), que se relaciona com a gestão superior da vida política do Estado; e outro nível, administrativo (em sentido estrito) que atende, num plano executivo, à realização prática das diretrizes legais e planejamentos necessários à execução da vontade política, coincidente (espera-se) com o interesse público (CUNHA JR., 2011, p. 31).

Como mencionamos em momento oportuno, nosso estudo se debruçará (por necessidades temáticas) sobre este segundo nível, o administrativo, o qual passaremos a analisar com mais atenção doravante.

\section{Enquadramento dos atos jurídicos de inteligência}

Torna-se assente, a esta altura, o enquadramento jurídico dos atos praticados no exercício da atividade de inteligência em segurança pública como "atos administrativos" sui generis (ou especiais), dada a especialidade do regime em que ocorre sua execução e o caráter diferenciado pelo qual sofrem a incidência dos princípios constitucionais. Cunha Jr. (2011, p. 100) conceitua atos administrativos como: "[...] espécie do gênero ato jurídico, regido pelo direito público, do qual se vale o Estado ou quem age em nome dele, para exprimir, unilateralmente, uma declaração de vontade, fundada na lei e voltada ao desempenho de funções administrativas na gestão do interesse coletivo".

O conceito deve ser complementado por Justen Filho (2009, p. 273):

O ato administrativo é uma 'manifestação de vontade', no sentido de que exterioriza a vontade de um sujeito dirigida a algum fim. Isso significa a existência de dois aspectos inconfundíveis na vontade. Há a exteriorização física, consistente numa ação ou omissão. Mas há também um aspecto interno, volitivo, que é a causa da ação ou omissão. (Grifo do autor).

$\mathrm{Na}$ esteira dessa compreensão, temos que os atos administrativos são, primeiramente, caracterizados por serem atos jurídicos, portanto, manifestações de vontade consciente, materiais ou reais, tendentes a produzir um efeito (ou consequência) previsto(a) em lei (GAGLIANO; PAMPLONA FILHO, 2009, p. 305).

Em segundo lugar, são atos praticados por um agente público devidamente investido em suas funções, preordenado à realização de uma finalidade estritamente pública (CARVALHO FILHO, 2013, p. 99), sob inexorável regime de direito público (ou seja, regrados por normas regentes de matéria de direito público, interessante, destarte, a toda a sociedade e sujeito a determinados imperativos de ordem).

Sob aspectos tipológicos, temos que os atos administrativos praticados em atividade de inteligência poderão ser, de acordo com as características, tanto vinculados ${ }^{5}$ quanto discricionários. ${ }^{6}$ Igualmente, sua classificação é variada conforme o efeito ocasionado pelo ato ou os responsáveis pela sua execução, questões que são despiciendas à presente análise.

Contudo é de extrema relevância a classificação dos atos finalísticos da atividade de inteligência em segurança pública como atos administrativos "de império", que são caracterizados por serem manifestações de vontade para as quais não concorre a vontade dos particulares, dos administrandos, quando de sua formação.

No bom dizer de Carvalho Filho (2013, p. 130), "os Atos de Império são os que se caracterizam pelo poder de coerção decorrentes do poder de império (ius imperii), não intervindo a vontade dos administrados para sua prática", definição que se conforma, perfeitamente, aliás, à esfera da atividade de inteligência.

\footnotetext{
"Art. 37. A administração pública direta e indireta de qualquer dos Poderes da União, dos Estados, do Distrito Federal e dos Municípios obedecerá aos princípios de legalidade, impessoalidade, moralidade, publicidade e eficiência".

Logo, com elementos estrita e totalmente amarrados em lei.

Consistindo em atos nos quais se dá margem ao administrador para uma atuação regida por critérios de conveniência e oportunidade (CARVALHO FILHO, 2013, p. 131), dando-Ihe liberdade quanto à escolha do objeto, desde que regularmente exposto o motivo do ato.
} 
Esse apontamento é de suma importância, afinal, os atos de império (em geral) são, inequivocamente, as espécies de atos administrativos que mais se denotam aptos a ocasionar potenciais violações aos direitos e garantias fundamentais do cidadão, o que, por óbvio, é ainda mais assente na categoria de atos administrativos praticados no exercício da atividade de inteligência.

Como bem assevera Gonçalves (2009, p. 56), "algumas dessas medidas limitarão, em algum momento, as liberdades individuais. Entretanto, ou as autoridades governamentais agem assim ou as consequências podem ser nefastas", afinal, a vedação à prática de atos dessa natureza, num contexto internacional e nacional de enfrentamento a organizações criminosas cada vez mais organizadas e estratificadas política e socialmente, significaria um "suicídio institucional" impensável.

Daí repetirmos: afigurando-se inconcebível abrir mão de uma atividade tão estratégica (como o é qualquer atividade desenvolvida dentro da Segurança Pública), deve-se buscar, por outro lado, sua legitimação através de eficientes mecanismos de controle legal e institucional.

Como bem afirma Marco Cepik (2001, p. 181), ao tratar dos "mandatos legais"7 da atividade de inteligência (num contexto internacional, aplicável, porém, ao âmbito interno),

\begin{abstract}
Claro está que os mandatos legais não resolvem os problemas políticos resultantes da interpretação sobre as áreas, os métodos e a intensidade da atuação da inteligência. [...] Entretanto, considerando-se que existem realmente ameaças que exijam a manutenção de organizações de security intelligence, os mandatos legais tornam-se imprescindíveis para ao menos estabelecer parâmetros a partir dos quais se possa julgar as ações e prioridades destes órgãos (CEPIK, 2001, p. 181).
\end{abstract}

$\mathrm{E}$, aqui, atingimos o cerne do primeiro momento de nosso estudo: compreendendo-se que os atos praticados no exercício da atividade de inteligência em segurança pública são efetivos "atos administrativos de império", podemos, a partir das características deste último, estabelecer critérios definidores da validade daqueles e sem, obviamente, olvidar suas especificidades e diferenciações.

Para tanto, devemos compreender a noção de "validade legal" daquela sorte de ato jurídico, bem como realizar uma detida análise sobre os elementos internos e externos conducentes à sua legitimação, conjecturas das quais nos ocuparemos no tópico seguinte, guiados, mais uma vez, pelas pertinentes estruturações científicas típicas do direito administrativo brasileiro.

\title{
5 Definição de "validade" e critérios internos e externos dos atos administrativos de império no Direito brasileiro
}

Objetivamente, podemos conceituar atos jurídicos no Direito brasileiro como declarações de vontade exaradas com o objetivo de produzir efeitos admitidos (ou seja, não proibidos) pelo direito (GAGLIANO; PAMPLONA FILHO, 2009, p. 315), no sentido de criar, modificar e extinguir direitos ou situações jurídicas.

Por óbvio, para que possam atingir suas finalidades pretendidas, é imprescindível que os atos jurídicos preencham pressupostos delineados pela própria lei, ou seja, obedeçam a determinados "planos jurídicos" pré-determinados.

O primeiro plano seria o da "existência", que materializa o "surgimento" do ato jurídico no mundo substancial, exigindo-se, para tanto, a manifestação de vontade de um agente através de suporte formal apropriado, voltado a certo objeto (finalidade da vontade) (GAGLIANO; PAMPLONA FILHO, 2009, p. 325).

O segundo plano é o da "validade", que configura a aceitação do ato existente pelos preceitos legais que lhe são próprios. Exige-se, assim, que o tenha sido praticado por agente capaz, através de uma forma não defesa por lei (ou por ela vinculada), voltando-se para objeto lícito possível e determinado ou determinável (GAGLIANO; PAMPLONA FILHO, 2009, p. 331-332). Note-se que um ato pode existir, porém não ser válido.

$\mathrm{Na}$ exposição de Cepik (2001, p. 178), a ideia de marcos legais se confunde com a ideia de "legalidade" aqui exposta, ou seja, a previsibilidade legal da adoção de "atos" de inteligência para fins de administração pública dos interesses sociais, notadamente, na área da segurança pública, no caso deste trabalho. 
Insta ressaltar que é sobre o critério da validade que o estudo se debruçará com detida atenção.

Por fim, temos o plano da "eficácia", que diz respeito à potencialidade do ato existente (e presumidamente válido) de gerar efeitos concretos no mundo substancial. Aqui se avalia sua sujeição a fatores temporais ou jurídicos capazes de limitar, ou postergar, a modificação material pretendida no mundo, bem como o momento em que aquele atinge a sociedade e produz consequências (GAGLIANO; PAMPLONA FILHO, 2009, p. 403-404).

A compreensão desses planos é de fundamental importância porque, em termos práticos, embora o "natural" seja a plena satisfação dos planos jurídicos inerentes aos atos praticados no âmbito estatal, não é incomum constatar, tanto na esfera pública quanto na privada, a presença de "ações" que, embora existentes e eficazes (já produzindo efeitos concretos, portanto), carecem de efetiva validade.

Essa "invalidade" - grave, como o nome já sugere-, acaba por passar desapercebida em razão da uma incompreensão coletiva a respeito dos elementos que the são intrínsecos. Numa hipótese otimista, poderia até se falar na "convalidação" do ato (ou seja, correção do elemento ausente ou defeituoso). Mas, em grande parte dos casos, o caminho inafastável é o da anulação administrativa ou judicial (sem prejuízo de eventuais compensações ou reparação de danos eventualmente causados).

Os mesmos planos jurídicos são aplicáveis aos atos "jurídico-administrativos" do Estado, os quais, entretanto, detém elementos (componentes) diferenciados dos atos jurídicos civis ou comuns.

Conforme ensina Carvalho Filho (2013, p. 106), nos termos da doutrina predominante, os atos administrativos são compostos por cinco elementos necessários à sua validade, quais sejam: a) competência; b) objeto; c) forma; d) motivo; e) finalidade.

Como regra geral, a ausência de um desses elementos importará na imediata nulidade do ato (ao menos, até sua convalidação), que, mesmo existente e eficaz, ainda assim poderá ocasionar severos prejuízos à administração pública, tanto num aspecto material (uma vez que poderá ser responsabilizada pela atuação irresponsável de um agente) como num aspecto político (uma vez que a nulidade pode importar num "descrédito" sobre sua atuação pública e política).

Especificamente, no que toca à Atividade de Inteligência, temos que o regime jurídico desses atos ganhará contornos diferenciados, justamente por conta das peculiaridades inerentes a essa atividade e sua "metodologia própria".

Portanto, nos tópicos subsequentes, nos dedicaremos à discussão em torno da verificação e discussão dessas peculiaridades, para que possamos compreender como funcionariam os mecanismos de controle de legalidade do ato jurídico-administrativo praticado na atividade de inteligência a partir de cada um daqueles elementos destacados.

\section{Análise dos elementos de validade dos atos jurídico-administrativos à luz das peculiaridades da Atividade de Inteligência}

O primeiro elemento a ser destacado em relação à análise da validade de um ato praticado em Atividade de Inteligência é a "competência" do agente que o efetivou, ou seja, a constatação se o ato praticado estava, ou não, na efetiva esfera de atribuições legais cometidas àquele agente, seja um analista, seja um agente de campo (operacional).

E é aqui que nos defrontamos com um dos principais problemas inerentes à validade jurídica dos atos jurídico-administrativos de inteligência: a regulamentação das ações dos agentes e analistas de inteligência, normalmente, é firmada no nível dos manuais das entidades que desempenham essa atividade, sem que a lei confira qualquer espécie de mandato ou autorização legal para que esses simples "digressos" realizem tamanha regulamentação.

Não se trata de uma problemática recente, diga-se de passagem. Conforme relata Figueiredo (2005, p. 113), ainda no ano de 1963, era relatado pelo então Chefe do Serviço Federal de Informações e Contra- 
Informações - SCIFI, o Tenente Coronel Carlos Ramos de Alencar, em conferência ministrada na Escola Superior de Guerra, que a legislação vigente à época era cheia de inconsistências que, além de tornar indefinida a competência do órgão (e, por via de consequência, de seus agentes), comprometia totalmente a eficiência do sistema de inteligência.

Em outras palavras, constata-se que muitas das ações praticadas por agentes e analistas de inteligência em segurança pública, em termos concretos, não encontram qualquer previsão legal que as ampare, o que, de pronto, importaria na invalidade daquelas, sujeitando-lhes a eventual declaração (judicial ou administrativa) de nulidade, dando azo a obrigações reparatórias ou compensatórias, conforme as peculiaridades da "ilegalidade" em cada caso.

A visibilidade desse problema, entretanto, é ocultada por uma série de problemas práticos relativos à análise judiciária da validade de ações de inteligência. Como aponta Cepik (2001, p. 182-186), a histórica visão de intangibilidade do mérito administrativo, ${ }^{8} \mathrm{o}$ "sigilo" inerente à atividade (que, muitas vezes, acaba por inviabilizar a noção de "contraditório e ampla defesa" judicial) e a existência de mecanismos refratários à atuação judiciária.

Ainda conforme Cepik (2001, p. 185), temos como muito mais comum a verificação de uma participação prévia do poder judiciário no controle de algumas ações de inteligência, como no caso das interceptações telefônicas, ${ }^{9}$ ações controladas ${ }^{10} \mathrm{e}$ infiltrações. ${ }^{11}$ Nas demais situações, até mesmo pela difícil caracterização dos ilícitos administrativos oriundos da atividade de inteligência, pouco se vê em termos de atuação judicial.

Ainda que pressupondo que os agentes ou analistas de inteligência sejam da área de segurança pública, estando conglobados, portanto, pelas competências gerais de seus cargos, deve-se lembrar que há uma diferença substancial entre as atividades de "investigação" e "repressão" de crimes e a atividade de "assessoramento" ao gestor, esta última realizada tipicamente em sede de atividade de inteligência, através de métodos próprios de coleta e análise de dados.

E, quando focamos sobre as práticas efetivadas nessa atividade (por exemplo, as "entradas", as "interceptações de sinais" e as "entrevistas"), constatamos que, diferentemente com o que ocorre em relação à interceptação telefônica, que detém tratamento legal próprio, não encontram qualquer espécie de previsão legal, capaz de admiti-las como exceções democraticamente consentidas em relação aos direitos fundamentais que atingem (como a inviabilidade domiciliar, diretamente afetada pela atividade de "entrada").

É claro que não se pode afirmar, inequivocamente, que tais atividades ainda sejam praticadas pelos órgãos de inteligência no Brasil. Sua previsão em sede de manuais, obviamente, não importa em sua adoção na prática, podendo ser justificada para fins de "análise histórica" ou "estudo global de técnicas".

Porém, ainda assim, é assente a inexistência de previsão legal das práticas, além daquelas previstas referidas em relação aos manuais, o que, por óbvio, gera um grave problema: não é possível, em muitos casos, aferir a competência do profissional de inteligência que eventualmente venha a praticar quaisquer das condutas próprias da atividade, o que pode infirmar de total nulidade a ação praticada.

O problema não se encerra por aí. É comum a "colaboração" de particulares que, de livre vontade ou mediante "incentivos", fornecem informações necessárias à apuração de fatos. Nessa qualidade, poderiam ser classificados, em sentido amplíssimo, como "agentes particulares colaboradores" (possivelmente, agente honoríficos, por prestarem informações por uma questão de "honra" à nação ou ao serviço público). ${ }^{12}$ Porém, novamente, não se constata qualquer espécie de regulamentação a respeito dessa possibilidade.

\footnotetext{
Mérito administrativo, conforme a doutrina de Carvalho Filho (2013, p. 125), pode ser compreendido como a esfera de "liberdade de escolha" atribuída política e legalmente aos agentes públicos pelo regime democrático, para que estes, atendendo a critérios de oportunidade e conveniência, que jamais poderiam ficar vinculados (amarrados em lei), possam fazer as "melhores escolhas" no atendimento das necessidades concretas do interesse público, evitando uma maior burocracia no atendimento das demandas do organismo social.

Lei 9.296/96, que regulamenta a interceptação telefônica tratada no teor do art. 5², XII, da Constituição da República Federativa do Brasil.

Art. $9^{\circ}$, da Lei $n^{\circ} 12.850 / 13$, que trata do combate a organizações criminosas.

Art. 10, da lei supramencionada.

Nesse sentido, recomenda-se a leitura de Carvalho Filho (2013, p. 591).
} 
Assim, vislumbra-se uma verdadeira "lacuna funcional" em nossa legislação a respeito do tratamento das ações dos profissionais da atividade de inteligência, o que pode gerar eventuais nulidades substancialmente graves e incompatíveis com a ideia de regime democrático vigente; além, obviamente, de trazer riscos que, por mais que consentidos, podem acabar por ser imputados exclusivamente ao analista ou agente da atividade em questão, num imoral benefício do ente estatal assessorado.

Por sua vez, é importante que seja verificado o "objeto da ação" praticada no ato de inteligência, situação que diz respeito "à criação, modificação ou extinção" que se pretende produzir na realidade jurídica pertinente. Em linhas simples, o "objeto" expressa o "conteúdo" da ação realizada, o que efetivamente "se fez" (JUSTEN FILHO, 2009, p. 295).

Esse objeto, por sua vez, deve ser lícito (ou seja, não deve ser proibido por lei), possível (ou seja, efetivamente realizável, em termos práticos) e determinado, ou, no mínimo, determinável (ou seja, deve ter sua extensão concreta passível de ser delimitada ou quantificada).

Como a atividade de inteligência é voltada para a obtenção de dados sensíveis ao processo decisório, no caso deste estudo, delimitado ao âmbito decisório das atividades de segurança pública, por óbvio, o objeto das ações de inteligência deverá se voltar para a obtenção de dados por meios legais (licitude), através de métodos legalmente viáveis (possibilidade) e voltadas a fatos devidamente especificados e delimitados (determinação), sobretudo em razão de que, no contexto democrático, a atividade de inteligência se encontra voltada aos fatos (e não a pessoas).

Inclusive, é de se afirmar que a atividade de inteligência em segurança pública não trabalha com "investigação", mas com atos voltados à coleta de dados necessários à convicção de gestores a respeito de fatos e fenômenos sociais, de modo a propiciar saberes fundamentais à tomada das melhores decisões possíveis (AZEVEDO; RICCIO; RUEDIGUER, 2011, p. 15).

Quando essa atividade trabalha com dados abertos (ou seja, publicamente disponíveis através de meios abertos de acesso, como prestações de contas, redes sociais, meios de comunicação etc.), nenhum problema se constata quanto a este objeto dos atos de inteligência (BARRETO; MIRANDA; NASCIMENTO, 2015, p. 135).

O mesmo já não se pode dizer a respeito da atividade destinada à obtenção de "dados negados", que pressupõem uma "acessibilidade não autorizada" pelos indivíduos e instituições. Num contexto democrático, só poderia ser consentida em duas hipóteses: a) quando há uma autorização legal para a acessibilidade desses dados (hipótese em que o objeto seria vinculado em lei), preenchidos certos requisitos; e b) há autorização discricionária concedida, conforme oportunidade ou conveniência, por um órgão ou instância colegiada (hipótese voltada a atos discricionários), o que, ainda assim, pressupõe previsão legal a respeito.

Quanto ao primeiro caso, observamos que existem leis prevendo essa possibilidade no Brasil, a exemplo das já referidas Lei $n^{\circ}$ 9.296/96 (que trata da interceptação telefônica) e Lei n 12.850/13 (A lei de combate a organizações criminosas, que trata da possibilidade de infiltração de agentes), em ambos os casos, sob estrita autorização judicial e após o preenchimento de determinados requisitos.

Algo que seria próximo do segundo exemplo é a previsão de uma comissão de controle e fiscalização externa em relação à Agência Brasileira de Inteligência, conforme previsão do art. $6^{013}$ da Lei n $n^{\circ} 9.883 / 99$. Falamos em "algo próximo", porque, a despeito da previsão legal desse órgão de controle externo, a lei deixou sob inteiro critério do Congresso Nacional a Institucionalização da Comissão, não especificando se o controle poderia ser "prévio", o que, por óbvio, não pode ser estipulado naquele ato regimental, justamente por significar uma ingerência em competências do Poder Executivo, e, assim, violação ao princípio constitucional da "separação das funções constitucionais". 13 "Art. 6o O controle e fiscalização externos da atividade de inteligência serão exercidos pelo Poder Legislativo na forma a ser estabelecida em ato
do Congresso Nacional.". 
Igualmente, questiona-se a "expressividade" da atuação daquele órgão.

Aqui, novamente, observamos que a falta de tratamento adequado a respeito dos "objetos", ou seja, dos "conhecimentos" passíveis de acesso no exercício da atividade de inteligência, sobretudo no que toca aos dados negados (que pressupõe uma invasão da esfera individual), o que, novamente, pode conduzir a ação tomada a uma situação de ilegalidade quanto à obtenção dos dados.

Por mais que tais dados não sejam (e nem possam ser) utilizados para fins de instrução criminal (já que essa não é a destinação da Atividade de Inteligência), ainda assim, sua obtenção pode ensejar "sentimentos" de "violação" substancialmente perigosos à estabilidade democrática, o que, por sua vez, impõe um tratamento mais adequado sobre a matéria.

Aqui, novamente, constatamos um dos problemas mais nevrálgicos.

A forma diz respeito ao "suporte" material através do qual o ato se realizará. A regra é a "solenidade" dos atos, ou seja, os mesmos devem ser elaborados por escrito, com perfeita identificação dos responsáveis, seguindo prescrições especificadas em normas legais ou regulamentares (CUNHA JR., 2011, p. 110).

Contudo, o que é regra para as demais atividades, é nítida exceção para a atividade de inteligência, como passamos a explicar.

Temos que as ações de inteligência devem ser compreendidas como um processo, ou, nos termos doutrinários, como um "ciclo", que, para ser consolidado como válido, depende da validade de uma série de outros atos.

Embora o ato final desse ciclo (em tese), o "Relatório de Inteligência" é um documento solene, portanto, escrito e elaborado conforme determinadas regras específicas. Em alguns casos, até com identificação (mesmo que criptografada) dos responsáveis, constata-se que os demais atos concretos, discricionários, realizados de forma inespecífica, conforme necessidades concretas de obtenção ou transmissão de informações sigilosas, não detém pormenorizações específicas afora as previstas nos manuais, o que torna a verificação de sua validade uma atividade hercúlea e praticamente impossível aos membros da própria equipe de inteligência em campo no momento da operação.

Certamente, é aqui que surge a maior necessidade de discussão, debate e construção de mecanismos de controle da "formalização" dos atos de inteligência, já que, nesse aspecto do ato jurídico-administrativo de inteligência, em sua materialização prática, em sua procedimentalização concreta, que podem ocorrer arbitrariedades contrárias ao espírito democrático.

No dizer de Cunha Jr. (2011, p. 111), o motivo "é a razão ou circunstância de fato ou de direito que autoriza ou determina a prática do ato administrativo". Em linhas mais simples, trata-se do "porquê" da prática de um ato.

Em sede de atividade de inteligência, deve-se lembrar que esse "motivo" sempre estará voltado à obtenção de dados qualificados, necessários à tomada de um processo decisório por parte de um gestor (CEPIK, 2001, p. 29), que se desenrola em diversas outras atividades de preparação, coleta e disseminação de informações.

A gênese da "solicitação de informações", por sua vez, que é primeiro passo do ciclo de inteligência, ocorre a partir da formalização da demanda de um agente de cúpula (o qual, normalmente, encontra-se subordinado ao órgão de inteligência), pleiteando uma determinada sorte de informações a respeito de um fato, o que, por óbvio, nasce como uma atitude legitimada pelo sistema político, materializando um verdadeiro "ato político". ${ }^{14}$

14 Conforme o ensinamento de Cunha Jr. (2011, p. 99), os atos políticos materializariam uma ação facultada pelos documentos políticos máximos de nossa federação (Constituição Federal, Constituições Estaduais e Leis Orgânicas), bem como, leis estratégicas, que permitiriam uma ação com "maior liberdade" a ser efetivada por parte de determinados grupos de agentes públicos (normalmente de cúpula, sendo, nessa qualidade, chamados de agentes políticos), conforme funções políticas concedidas diretamente pelo povo (mandato eleitoral) ou por autoridades eleitas (funções de confiança, por exemplo). 
Assim, todos os demais atos que decorrerem dessa solicitação (ato político) estarão, direta e exclusivamente, vinculados ao pedido (motivo da ação de inteligência), não devendo se estender, a princípio, a qualquer outro fato que não "o demandado" pela autoridade a ser assessorada, sob pena de violação dessa motivação, salvo quando influente na decisão a ser tomada, conforme margem discricionária eventualmente conferida por lei ao agente ou analista.

Há, portanto, uma vinculação do "motivo" e da "demanda" solicitada, que, se contrariada, poderá gerar a invalidade do ato jurídico-administrativo praticado em sede de atividade de inteligência.

Ademais, apesar do campo político não se configurar como objeto de análise (ao menos estrito) de nosso estudo, deve-se lembrar que a vontade política determinante do "motivo", se eventualmente corrompida, enseja "apego à legalidade" por parte dos executores das ações jurídico-administrativas de inteligência, de modo a, em último caso, até mesmo recursar a satisfação da demanda solicitada.

Trata-se de outro "gargalo" teórico digno de debate, uma vez que a vontade política corruptível pode ensejar motivos inválidos, porém vinculativos da ação dos agentes e analistas da atividade de inteligência. Desse modo, uma eventual recusa executiva legítima por parte destes últimos pode acabar por ser substituída por um "acatamento tácito" de arbitrariedades, ainda mais no Brasil, onde a meritocracia é sinônimo de subserviência quando da eleição dos ocupantes de cargos de confiança. Trata-se, portanto, de sério ponto a ser analisado além da legalidade, invadindo o campo teórico, político e ético.

Finalmente, temos como assente na doutrina do direito administrativo que a "finalidade" é um elemento vinculado de conteúdo irredutível: "[...] toda atividade desenvolvida pela administração pública deve guiar-se para o atendimento de um único resultado ou bem jurídico, qual seja, o fim público, que nada mais é senão servir ao interesse da coletividade." (CUNHA JR., 2011, p. 109).

Trata-se de uma consequência "mediata" que deve ser almejada em relação aos atos administrativos em geral, não o sendo diferente em relação aos atos jurídico-administrativos praticados na atividade de inteligência.

Cepik (2001, p. 28) afirma que, pela natural subsidiariedade da atividade de inteligência, pode ser compreendida como um "subconjunto" do próprio "ciclo das políticas públicas", sendo desempenhada como uma função que deve estar voltada ao fornecimento de informação qualificada e embasada, para permitir ao gestor (materializador das políticas que atenderão, conforme critérios constitucionais, ao que é de interesse coletivo) à tomada de decisões corretas em prol da comunidade.

Novamente, deve-se lembrar que a noção de "interesse público" aqui utilizada perpassa por toda a discussão de democracia já realizada no segundo tópico deste estudo, não devendo, nem de longe, ser compreendida como uma utopia capaz de conglobar todos os interesses existentes no organismo social.

O que se deve ter em mente, em relação à finalidade, é que um ato de inteligência válido é aquele desempenhado em prol do atingimento de um objeto lícito (finalidade imediata), conforme uma necessidade declarada pelo detentor de um mandato político-jurídico competente, por sua vez, para acionar os órgãos de inteligência (motivo).

O caráter finalístico do ato (a satisfação do que é de interesse público), portanto, acaba por dizer respeito a questões que ultrapassam, novamente, a esfera da legalidade, habitando o campo da "política" e da "vontade" representativa, declarada pelos agentes escolhidos conforme os processos institucionalizados pela Constituição Federal e pela Lei (eleição direta ou indireta, nomeação para ocupação de cargos de confiança, etc.).

Por óbvio, "escolhas" realizadas pelos administradores em desrespeito ao mínimo processo democrático instituído, decerto, significarão uma violação da finalidade pública ora referida, importando, por sua vez, na nulidade de toda e qualquer atividade desempenhada pelos órgãos de inteligência.

É por isso que, mais uma vez, reforçamos a importância do controle político exercido pelo Poder Legislativo em relação à atividade de inteligência, o qual, no nível federal, repita-se, foi instituído pela 
própria Lei 9.883/99, que, em seu art. $6^{\circ}$, instituiu a comissão de controle e fiscalização externa em relação à Agência Brasileira de Inteligência.

Essa comissão, regida pela Resolução nº 02/2013 do Congresso Nacional, detém a função de fiscalização e controle externo da atividade de inteligência desempenhada pela Agência Brasileira de Inteligência - ABIN e demais órgãos do Sistema Brasileiro de Inteligência - o SISBIN, por óbvio, não só de maneira restrita ao aspecto de legalidade que embasa este estudo, mas num aspecto muito mais amplo, conglobando a conveniência política das ações realizadas.

A despeito do caráter elogioso da iniciativa, constata-se a não reprodução obrigatória desse mecanismo de controle no âmbito dos Estados e Municípios, enfraquecendo o necessário e imprescindível controle de finalidade dos atos jurídico-administrativos realizados pelos órgãos de inteligência desses entes federativos, sobretudo no campo da Segurança Pública, onde é marcante a atuação, sobretudo, dos Estados de nossa federação.

Igualmente, o já registrado "trauma histórico" associado à atividade de inteligência, ligado à ausência de transparência política (questão que não se restringe somente ao âmbito da atividade de inteligência, diga-se de passagem) são fatores que dificultam substancialmente a legitimação e, nessa senda, a criação de mecanismos de controle da legalidade (e, portanto, da finalidade) dos atos jurídico-administrativos praticados no exercício daquela função.

Cabe, por hora, a transcrição de importante conclusão obtida por Cepik (2001, p. 214) a respeito das questões políticas que envolvem a atividade:

\footnotetext{
[...] Mesmo nos países mais democráticos os mecanismos de supervisão congressual são muito recentes e têm evidentes problemas de desempenho institucional. Na medida em que a institucionalização dos serviços de inteligência envolveria não apenas a obtenção de 'estabilidade' organizacional, mas também um longo processo através do qual eles tornam-se (ou não) organizações valiosas para o público, esse é um processo que está fortemente relacionado à transparência, ou seja, à capacidade do público ver e julgar por si mesmo os atos dos governantes na área de inteligência. Mesmo que os serviços de inteligência contemporâneos tornem-se suficientemente ágeis para estabilizarem-se organizacionalmente no novo contexto [...], sua eventual institucionalização dependerá ainda da difícil resolução do dilema da transparência.
}

Portanto, longe de analisar a finalidade com a simplicidade costumeira da ciência jurídica, temos que o atendimento ao "interesse público", num contexto democrático de interesses divergentes, em verdade, é um critério legislativo meramente retórico que, na prática, só se realiza mediante a existência de órgãos de controle (sobretudo legislativos) que garantam a transparência do processo político de uso dos órgãos de inteligência, obviamente, respeitando seu sigilo e o caráter fundamentalmente estratégico de suas funções.

\section{Conclusão}

Faltando praticamente uma década para a comemoração do centenário da institucionalização da atividade de inteligência no Brasil (ainda em 1927, no Governo Washington Luis), temos que essa função ainda convive com sérios problemas contemporâneos ao seu nascedouro, os quais são concernentes, sobretudo, à indiferença quanto à normatização de sua metodologia e práticas, o que, por sua vez, só reforça, na atualidade, o "temor" criado em torno de sua prática e de seus "fantasmas", remanescentes de regimes autoritários.

Como constatamos ao longo do estudo, uma vez verificada a natureza jurídico-administrativa dos atos praticados na atividade de inteligência, vislumbrou-se também, a partir de nossa legislação, a possibilidade de aferir critérios mínimos para avaliar a validade daqueles atos.

Das construções doutrinárias do direito administrativo, por sua vez, constatou-se o caráter público da atividade de inteligência em segurança pública, bem como sua submissão às normas de mesma natureza e a princípios constitucionais inerentes à atividade administrativa como um todo. 
De igual maneira, constatou-se a existência de graves lacunas quanto aos elementos definidores da validade dos atos praticados no exercício da atividade de inteligência, capazes de ocasionar, num primeiro momento, a declaração de nulidade das ações realizadas e, como consequência, possíveis prejuízos financeiros aos entes públicos envolvidos na "violação da legalidade".

Numa perspectiva mais grave, temos que essa fragilidade de limites pode importar num "descrédito" em relação às instituições políticas e administrativas, além de uma total contrariedade ao espírito democrático, significando violações não consentidas aos núcleos intangíveis de certos direitos fundamentais do cidadão.

Faz-se necessário, portanto, um aprimoramento de nossa legislação quanto aos elementos configuradores da validade dos atos jurídico-administrativos desempenhados na inteligência (competência, objeto, forma, motivo e finalidade), bem como, além do aspecto da legalidade, o fortalecimento de instituições de controle político institucional dessa atividade, justamente para que, superando as cicatrizes do passado, a função em apreço tenha reconhecida sua legitimidade democrática e seu caráter de imprescindibilidade à mantença da ordem social.

Para tanto, faz-se necessária uma desmistificação da atividade de inteligência, sua apresentação formal à comunidade e sua submissão a debates e estudos abertos, como o ora efetivado, de modo a admiti-la como significativo instrumento evolutivo disponível para o Estado brasileiro, sobretudo no aspecto tangente à segurança pública.

Por óbvio, o presente estudo não se encerra em si mesmo, mas dá azo a um prosseguimento da análise por vieses históricos, políticos e jurídicos mais aprofundados, que buscarão as origens (pretendidas ou não; convenientes ou não) de tantas lacunas normativas no regramento desse importante campo político.

Devemos encerrar essas ponderações afirmando que a atividade de inteligência empodera o regime democrático, permitindo a antecipação de eventos muito prejudiciais à ordem social, inclusive se sujeito a um coerente controle de finalidade, capaz de potencializar a participação de camadas não hegemônicas de nosso organismo social, aproximando da realidade concreta o proclamado "mito da igualdade", típico do nosso modelo político.

Contudo, isto pressupõe uma crença da comunidade de inteligência e no aprimoramento de suas ações, na eticidade de suas atribuições e, sobretudo, na pluralidade político-institucional, que impõe controlar e aceitar o controle, como garantia, justamente, de transparência na satisfação das necessidades públicas.

Aprimorar é preciso. Se o Brasil ainda não acredita, hoje, na comunidade de inteligência, a comunidade de inteligência, certamente, como visionária por aptidão natural que é, tem muitos motivos para acreditar no Brasil.

\section{Referências}

ANTUNES, Priscila Carlos Brandão. SNI E ABIN: entre a teoria e a prática. Uma leitura da atuação dos serviços secretos brasileiros ao longo do século XX. Rio de Janeiro: Fundação Getúlio Vargas, 2002.

AZEVEDO, Ana Luísa Vieira de; RICCIO, Vicente; RUEDIGER, Marco Aurélio. A utilização das estatísticas criminais no planejamento da ação policial: cultura e contexto organizacional como elementos centrais à sua compreensão. CI. Inf., Brasília, v. 40, n. 1, jan./abr. 2011.

BARRETO, Erick Fleming Roque; MIRANDA, Wando Dias; NASCIMENTO, D.M. A obtenção de dados em fontes abertas na atividade de inteligência de Segurança Pública do Estado do Pará: desafios e possibilidades na sua utilização. In: NASCIMENTO, D. M. (Org.) et al. Defesa e criminalidade. Belém: NAEA/UFPA, 2015. p. 133-156.

BEHRING, Elaine Rossetti; BOSCHETTI, Ivanete. Política social: fundamentos e história. São Paulo: Cortez, 2006.

BRASIL. Ministérios da Justiça. Secretaria Nacional de Segurança Pública. Doutrina nacional de inteligência de segurança pública. 2. ed. Brasília: Coordenadoria-Geral de Inteligência, 2009. 
BRASIL. Constituição (1988). Constituição da República Federativa do Brasil. Disponível em: <http:// www.planalto.gov.br/ccivil_03/constituicao/constituicao.htm>. Acesso em: 08 jan. 2018.

BRASIL. Lei $\mathbf{n}^{\circ}$ 9.296, de 24 de junho de 1996. Regulamenta o inciso XII, parte final, do art. $5^{\circ}$ da Constituição Federal. Disponível em: <http://www.planalto.gov.br/ccivil_03/leis/L9296.htm>. Acesso em: 05 jan. 2018.

BRASIL. Lei $\mathbf{n}^{\circ} \mathbf{1 2 . 8 5 0}$, de 02 de agosto de 2013. Define organização criminosa e dispõe sobre a investigação criminal, os meios de obtenção da prova, infrações penais correlatas e o procedimento criminal; altera o Decreto-Lei no 2.848, de 7 de dezembro de 1940 (Código Penal); revoga a Lei no 9.034, de 3 de maio de 1995; e dá outras providências. Disponível em: <http://www.planalto.gov.br/ ccivil_03/_ato2011-2014/2013/lei/l12850.htm>. Acesso em: 12 dez. 2017.

BRASIL. Lei n 9.883, 07 de dezembro de 1999. Institui o Sistema Brasileiro de Inteligência, cria a Agência Brasileira de Inteligência - ABIN, e dá outras providências. Disponível em: <http://www.planalto. gov.br/ccivil_03/leis/L9883.htm>. Acesso em: 12 dez. 2017.

CANO, Oscar A. C. Inteligência nacional. Buenos Aires: Esnaola, 1965.

CARVALHO FILHO, José dos Santos. Manual de direito administrativo. 26. ed. São Paulo: Atlas, 2013.

CEPIK, Marcos Aurélio Chaves. Serviços de inteligência: agilidade e transparência como dilemas de institucionalização. 2001. Tese (Doutorado em Ciência Política) - Instituto Universitário de Pesquisas do Rio de Janeiro. Rio de Janeiro, 2001.

CEPIK, Marco; KUELE, Giovanna. Inteligência em operações de paz da ONU: déficit estratégico, reformas institucionais e desafios operacionais. Dados, Rio de Janeiro, v. 59, n. 4, p. 963-993, out. 2016. Disponível em: <http://www.scielo.br/scielo.php?script=sci_arttext\&pid=S0011-52582016000400963\&Ing =pt\&nrm=iso>. Acesso em: 11 jan. 2018.

CUNHA JR., Dirley da. Curso de direito administrativo. 10. ed. Salvador: Jus Podivm, 2011.

FARIAS NETO, Pedro Sabino de. Ciência política: enfoque integral avançado. São Paulo: Atlas, 2011.

FERNANDES, Bernardo Gonçalves. Curso de direito constitucional. 6. ed. Salvador: Jus Podivm, 2014.

FIGUEIREDO, Lucas. O ministério do silêncio: a história do Serviço Secreto Brasileiro de Washington Luís a Lula - 1927-2005. Rio de Janeiro: Record, 2005.

FOUCAULT, Michel. A microfísica do poder. Organização, tradução e revisão técnica de Roberto Machado. 2. ed. Rio de Janeiro: Paz e Terra, 2015.

GAGLIANO, Pablo Stolze; PAMPLONA FILHO, Rodolfo. Novo curso de direito civil: parte geral. 11. ed. São Paulo: Saraiva, 2009. v. I.

GONÇALVES, Joanisval Brito. Atividade de inteligência e legislação correlata. Niterói: Impetus, 2009. JUSTEN FILHO, Marçal. Curso de direito administrativo. 4. ed. São Paulo: Saraiva, 2009.

MARCHESINI DE PÁDUA, Elisabete Matalo. O trabalho monográfico como iniciação à pesquisa científica. In: CARVALHO, Maria Cecília Maringoni de. Construindo o saber: metodologia científica fundamentos e técnicas. 24. ed. São Paulo: Papirus, 2012. p. 147-170.

MIGUEL, Luis Felipe. Violência e política. Revista Brasileira de Ciências Sociais, Brasília, v. 30, n. 88, 2015. Disponível em: <http://www.scielo.br/pdf/rbcsoc/v30n88/0102-6909-rbcsoc-30-88-0029.pdf>. Acesso em: 09 jan. 2018.

MEZZAROBA, Orides; MONTEIROS, Cláudia Servilha. Manual de metodologia da pesquisa no direito. 6. ed. São Paulo: Saraiva, 2014.

SANTOS, Boaventura de Souza. Pela mão de Alice: o social e o político na pós-modernidade. 14. ed. São Paulo: Cortez, 2013. 
SANTOS, Roberto Ferreira. $\mathbf{O}$ arcabouço legal da atividade de inteligência do Brasil: entre a eficiência e o controle. 2015. 89 f. Monografia (Direito) - Universidade de Brasília, Brasília, 2015. Disponível em: <http://bdm.unb.br/bitstream/10483/11013/1/2015_RobertoFerreiradosSantos.pdf>. Acesso em: 11 jan. 2018.

STEELE, Robert D. On intelligence: spies and secrecy in an open world. Oakton: OSS International Press, 2001.

Recebido em: 11/01/2018

Aprovado em: 11/09/2018 